\title{
Effect of Asafoetida Extract on Growth and Quality of Pleurotus ferulic
}

\author{
Zuoshan Feng ${ }^{1,2}$, Yujia Bai ${ }^{2}$, Fanglin Lu ${ }^{1}$, Wenshu Huang ${ }^{2}$, Xinmin $\mathrm{Li}^{3}$ and Xiaosong Hu ${ }^{1, *}$ \\ 1 College of Food Science and Nutritional Engineering, China Agricultural University, Beijing 10083, \\ China; E-Mails: fengzuoshan@126.com (Z.F.); lindalu101@yahoo.cn (F.L.) \\ 2 College of Food Science Xinjiang Agricultural University, Ulumuqi, Xinjiang 830052, China; \\ E-Mails: xjnd-hws@126.com (W.H.); saintbyj@126.com (Y.B.) \\ 3 Gansu Agricultual Institute of Sciences, Lanzhou, Gansu 730010, China;
}

E-Mail: lixinming4@126.com (X.L.)

* Author to whom correspondence should be addressed; E-Mail: huxiaos@263.net; Tel.: +86-010-62737434; Fax: 86-010-62737434.

Received: 30 October 2009; in revised form: 3 December 2009 / Accepted: 28 December 2009 / Published: 29 December 2009

\begin{abstract}
Different concentrations of asafoetida extract were added to the medium of Pleurotus ferulic and the effects of the extract on growth of P. ferulic mycelium and fruiting bodies was observed. As the amount of asafoetida extract additive was increased, the growth of Pleurotus mycelium was faster, the time formation of buds was shorter and that yield of fruiting bodies was stimulated. However, overdosing of asafoetida extract hampered the growth of Pleurotus ferulic. The amino acid composition and volatile components in three kinds of pleurotus' were contrasted, including wild pleurotus (WP), cultivated pleurotus with asafoetida extract (CPAE) and cultivated pleurotus without asafoetida extract (CP). CPAE with $2.3 \mathrm{~g} / 100 \mathrm{~g}$ asafoetida extract addition had the highest content of total amino acids, as well as essential amino acids. WP had a higher content of total amino acids and essential amino acids than CP. In addition, CPAE with $2.3 \mathrm{~g} / 100 \mathrm{~g}$ had the highest score of protein content of pleurotus fruiting bodies, while WP had a higher score than CP. In the score of essential amino acid components of pleurotus fruiting bodies, CP had the highest score, while CPAE was higher than WP. Asafoetida extract influenced the volatile components of Pleurotus ferulic greatly, making the volatile components of cultivated pleurotus more similar to those of wild pleurotus (WP).
\end{abstract}


Keywords: Pleurotus ferulic; asafoetida extract; amino acids; volatile components

\section{Introduction}

Pleurotus ferulic [1,2], whose Latin name is Pleuratus eryngii (Dc, ex, Fr)Quelet, belongs to Enmycophyta, Basidiomycetes, Agarieales, Pleurotaceae, Pleurotus. It mainly parasitizes or saprophytes the roots of samphire spp., like asafoetida (Ferula sinkiangensis K. M. Shen) [3]. The growth of cultivated pleurotus is affected not only by conditions like species, the environment and the nutrient contents of the medium, but also by some small organic molecules, like plant hormones, and secondary metabolites [4,5]. Wild Pleurotus ferulic as a parasitie or saprophyte in the roots and stems of asafoetida is highly undividedly. This kind of special relationship is thought to have developed due to long-time adaptation, evolution and heredity but the relationships establishing heredity have not been established. The components of asafoetida must influence the growth, nutrient, and flavor formation [6], although selected cultivated Pleurotus ferulic species can grow well without asafoetida, Researchers have investigated the influence of asafoetida content in the medium of Pleurotus ferulic on its growth and nutrients. The results showed that the P. ferulic with asafoetida powder had a relatively higher quality, that its mycelium grew faster and more exuberantly, and that its amino acids levels were apparently higher than without asafoetida powder [7]. Research on the influence of four kinds of Traditional Chinese Medicine samphire extracts including asafoetida, saposhnikovia, bupleurum, and nodakenin on Braun pleurotus K3 mycelium, showed that the appropriate concentrations of the four kinds of extract can all prompt the growth of B. pleurotus mycelium [8].

In this research asafoetida extract was added to the Pleurotus medium in order to examine the influence of the extract on the growth, amino acids and volatile components of Pleurotus ferulic, indicating its influence on the nutrients and flavor and providing a research foundation for the coordination of growth, quality enhancement, and flavor improvement of this product.

\section{Results and Discussion}

\subsection{Effect of Asafoetida Extract on Pleurotus Mycelium Growth}

According to Table 1, asafoetida extract can improve mycelium growth. Except for the $0.3 \mathrm{~g} / 100 \mathrm{~g}$ asafoetida extract treatment, which showed little difference with $\mathrm{CP}$, other treatments have all shown obvious effects. For example, in the $0.8 \mathrm{~g} / 100 \mathrm{~g}$ treatment, mycelium grew to fill plastic bags (i.e., grew to a length of $15.0 \mathrm{~cm}$ ) after only 38 days, two days earlier than CP (40 days); in the $1.3 \mathrm{~g} / 100 \mathrm{~g}$ and $1.8 \mathrm{~g} / 100 \mathrm{~g}$ treatments, mycelium filled the plastic bags in both cases within 37 days, three days earlier that $\mathrm{CP}$; in the $2.3 \mathrm{~g} / 100 \mathrm{~g}$ and $2.8 \mathrm{~g} / 100 \mathrm{~g}$ treatments, mycelium grew to fill plastic bags within 36 days, four days earlier that $\mathrm{CP}$, while mycelium grew more thickly than in the case of $\mathrm{CP}$; in the $3.3 \mathrm{~g} / 100 \mathrm{~g}$ treatment, mycelium grew to fill the plastic bags earlier than CP by two days, however, the rate of growth and the quality and thickness of mycelium were not as good as seen for the $2.3 \mathrm{~g} / 100 \mathrm{~g}$ and $2.8 \mathrm{~g} / 100 \mathrm{~g}$ treatments. This means that within some specific concentrations, as the the amount of 
asafoetida extract additive increases, growth of Pleurotus mycelium was faster, but that an overdose of asafoetida extract can inhibit mycelium growth.

Table 1. Effect of asafoetida extract on pleurotus mycelium growth.

\begin{tabular}{cccccccccccccc}
\hline Treatment & 7d & 14d & 21d & 28 & 35d & 36d & 37d & 38d & 39d & 40d & $\begin{array}{c}\text { Average mycelium } \\
\text { length (cm/d) }\end{array}$ & $\begin{array}{c}\text { Growth } \\
\text { condition }\end{array}$ \\
\hline $0 \mathrm{~g}(\mathrm{CP})$ & 0.3 & 3.6 & 6.8 & 9.4 & 11.8 & 12.3 & 12.8 & 13.6 & 14.4 & 15.0 & & 0.375 & + \\
$0.3 \mathrm{~g}$ & 0.3 & 3.6 & 6.9 & 10.0 & 12.7 & 13.2 & 13.7 & 14.1 & 14.6 & 15.0 & 0.375 & + \\
$0.8 \mathrm{~g}$ & 0.4 & 3.7 & 6.9 & 10.0 & 12.9 & 13.5 & 14.4 & 15.0 & 15.0 & 15.0 & 0.395 & ++ \\
$1.3 \mathrm{~g}$ & 0.3 & 3.6 & 6.8 & 10.5 & 13.9 & 14.5 & 15.0 & 15.0 & 15.0 & 15.0 & 0.405 & +++ \\
$1.8 \mathrm{~g}$ & 0.4 & 3.7 & 6.9 & 10.6 & 13.9 & 14.8 & 15.0 & 15.0 & 15.0 & 15.0 & 0.405 & +++ \\
$2.3 \mathrm{~g}$ & 0.5 & 3.8 & 7.0 & 10.7 & 14.0 & 15.0 & 15.0 & 15.0 & 15.0 & 15.0 & 0.417 & ++++ \\
$2.8 \mathrm{~g}$ & 0.4 & 3.7 & 6.9 & 10.6 & 13.8 & 15.0 & 15.0 & 15.0 & 15.0 & 15.0 & & 0.417 & ++++ \\
$3.3 \mathrm{~g}$ & 0.4 & 3.7 & 6.9 & 9.6 & 12.9 & 13.8 & 14.5 & 15.0 & 15.0 & 15.0 & & 0.395 & +++
\end{tabular}

Date stands for the average level of each treatment;,,,++++++++++ means the growth of mycelium is diminishing.

\subsection{Effect of Asafoetida Extract on the Generation of Pleurotus Buds}

Table 2 demonstrates that the generation of Pleurotus buds was obviously promoted by the increasing concentration of asafoetida extract from $0.3 \mathrm{~g} / 100 \mathrm{~g}$ to $2.8 \mathrm{~g} / 100 \mathrm{~g}$. However, further research confirmed that asafoetida extract at a concentration of about $3.3 \mathrm{~g} / 100 \mathrm{~g}$ resulted in the inhibition of generation of buds.

Table 2. Effect of asafoetida extract on the generation and number of Pleurotus buds.

\begin{tabular}{ccccccccc}
\hline Treatment & 125d & 128d & 131d & 134d & 137d & 140d & 143d & 146d \\
\hline $0 \mathrm{~g}(\mathrm{CP})$ & & & & & 14 & 36 & 45 & 50 \\
$0.3 \mathrm{~g}$ & & & & 12 & 22 & 38 & 50 & 50 \\
$0.8 \mathrm{~g}$ & & 1 & 10 & 30 & 46 & 50 & 50 & 50 \\
$1.3 \mathrm{~g}$ & & 2 & 12 & 24 & 40 & 50 & 50 & 50 \\
$1.8 \mathrm{~g}$ & & 1 & 7 & 25 & 28 & 42 & 46 & 50 \\
$2.3 \mathrm{~g}$ & 1 & 6 & 11 & 24 & 45 & 50 & 50 & 50 \\
$2.8 \mathrm{~g}$ & & 5 & 19 & 31 & 40 & 50 & 50 & 50 \\
$3.3 \mathrm{~g}$ & & 4 & 4 & 14 & 26 & 47 & 50 & 50 \\
\hline
\end{tabular}

\subsection{Effect of Asafoetida Extract on the Yield of Pleurotus Fruiting Bodies}

Comparable fruiting body growth characteristics were observed in culture medium supplemented with asafoetida extract (Table 3). In culture medium, supplementation with asafoetida extract from $0.3 \mathrm{~g} / 100 \mathrm{~g}$ to $2.3 \mathrm{~g} / 100 \mathrm{~g}$ significantly promoted growth of Pleurotus fruiting bodies (Table 3), and a maximum yield of fruiting bodies was obtained at a concentration of about $2.3 \mathrm{~g} / 100 \mathrm{~g}$. The results 
showed that the asafoetida extract was closely associated or correlated $(\mathrm{R}=0.895)$ with the growth of ies over most of the culture period.

Table 3. Effect of asafoetida extract on the yield of pleurotus fruiting bodies.

\begin{tabular}{cccc}
\hline Treatment & $\begin{array}{c}\text { Average weight } \\
(\mathbf{g} / \mathbf{b a g})\end{array}$ & $\begin{array}{c}\text { Total weight } \\
(\mathbf{g})\end{array}$ & $\begin{array}{c}\text { Increased percent } \\
(\mathbf{\%})\end{array}$ \\
\hline $0 \mathrm{~g}(\mathrm{CP})$ & 8.2 & 410.0 & - \\
$0.3 \mathrm{~g}$ & 10.0 & 500.0 & $21.95 \%$ \\
$0.8 \mathrm{~g}$ & 13.7 & 685.0 & $67.07 \%$ \\
$1.3 \mathrm{~g}$ & 14.3 & 715.0 & $74.39 \%$ \\
$1.8 \mathrm{~g}$ & 16.3 & 815.0 & $98.78 \%$ \\
$2.3 \mathrm{~g}$ & 19.6 & 980.0 & $139.02 \%$ \\
$2.8 \mathrm{~g}$ & 17.4 & 870.0 & $112.20 \%$ \\
$3.3 \mathrm{~g}$ & 17.4 & 870.0 & $112.20 \%$ \\
\hline
\end{tabular}

\subsection{Effect of Asafoetida Extract on the Amino Acids Components of Pleurotus Fruiting Body}

We chose CPAE with $2.3 \mathrm{~g} / 100 \mathrm{~g}$ extract for the experiment to assess Pleurotus ferulic amino acids, because CPAE with this extract concentration promoted mycelium and fruiting body growth, with high yields of fruiting bodies. This means CPAE with $2.3 \mathrm{~g} / 100 \mathrm{~g}$ extract had higher bioconversion efficiency and bio-conversion rate, increasing the accumulation of nutrients. It is necessary for us to analyze the amino acid proportion ratios of protein, an important nutrient, to make an assessment of protein levels.

As illustrated in Table 4, the amino acid assessment experimental results showed that total amino acid in Pleurotus ferulic fruiting bodies was the highest in CPAE with $2.3 \mathrm{~g} / 100 \mathrm{~g}$ extract, following by WP, CP. However, amino acid composition after different treatments varies differently, as the did the content of seven amino acids Asp, Thr, Ser, Glu, Gly, Ala and Pro, which was higher in WP than in $\mathrm{CP}$, followed by CPAE with $2.3 / 100 \mathrm{~g}$ extract; the content of Val in WP is higher than CPAE, followed by CP; the content of Lys in CPAE is the same as CP, but lower that WP.

Table 4. Amino acids components of Pleurotus fruiting bodies.

\begin{tabular}{cccc}
\hline \multirow{2}{*}{ Amino acid } & \multicolumn{3}{c}{ Content ( amino acids g/100 g dry Pleurotus) } \\
\cline { 2 - 4 } & WP & CP & $\begin{array}{c}\text { CPAE with } \\
\mathbf{2 . 3} \text { g/100 g extract }\end{array}$ \\
\hline Asp $^{* *}$ & $3.40 \pm 0.03^{\mathrm{A}}$ & $3.30 \pm 0.03^{\mathrm{A}}$ & $2.90 \pm 0.07^{\mathrm{B}}$ \\
Thr $^{*}$ & $1.10 \pm 0.07^{\mathrm{a}}$ & $0.90 \pm 0.03^{\mathrm{b}}$ & $0.85 \pm 0.03^{\mathrm{b}}$ \\
Ser $^{* *}$ & $1.20 \pm 0.03^{\mathrm{A}}$ & $0.98 \pm 0.04^{\mathrm{A}}$ & $0.86 \pm 0.01^{\mathrm{B}}$ \\
Glu $^{*}$ & $3.40 \pm 0.03^{\mathrm{A}}$ & $3.20 \pm 0.06^{\mathrm{B}}$ & $3.10 \pm 0.04^{\mathrm{B}}$ \\
Gly $^{* *}$ & $1.30 \pm 0.04^{\mathrm{A}}$ & $1.10 \pm 0.03^{\mathrm{B}}$ & $1.00 \pm 0.04^{\mathrm{B}}$ \\
Ala $^{* *}$ & $2.20 \pm 0.04^{\mathrm{A}}$ & $1.50 \pm 0.03^{\mathrm{B}}$ & $1.30 \pm 0.01^{\mathrm{B}}$ \\
Val $^{* *}$ & $1.30 \pm 0.01^{\mathrm{A}}$ & $0.75 \pm 0.01^{\mathrm{C}}$ & $0.96 \pm 0.03^{\mathrm{B}}$ \\
Met $^{* *}$ & $0.06 \pm 0.04^{\mathrm{C}}$ & $0.14 \pm 0.01^{\mathrm{B}}$ & $0.23 \pm 0.01^{\mathrm{A}}$ \\
\hline
\end{tabular}


Table 4. Cont.

\begin{tabular}{lccc}
\hline Ile $^{* *}$ & $0.95 \pm 0.03^{\mathrm{B}}$ & $0.72 \pm 0.03^{\mathrm{C}}$ & $1.60 \pm 0.04^{\mathrm{A}}$ \\
Leu $^{* *}$ & $1.70 \pm 0.03^{\mathrm{B}}$ & $1.40 \pm 0.04^{\mathrm{C}}$ & $2.40 \pm 0.07^{\mathrm{A}}$ \\
Tyr $^{* *}$ & $1.70 \pm 0.04^{\mathrm{C}}$ & $2.10 \pm 0.03^{\mathrm{B}}$ & $3.80 \pm 0.08^{\mathrm{A}}$ \\
Phe $^{*}$ & $1.00 \pm 0.06^{\mathrm{A}}$ & $0.83 \pm 0.03^{\mathrm{B}}$ & $1.10 \pm 0.03^{\mathrm{A}}$ \\
His $^{* *}$ & $0.66 \pm 0.03^{\mathrm{B}}$ & $0.53 \pm 0.01^{\mathrm{C}}$ & $0.88 \pm 0.01^{\mathrm{A}}$ \\
Lys $^{* *}$ & $1.40 \pm 0.00^{\mathrm{a}}$ & $1.10 \pm 0.04^{\mathrm{b}}$ & $1.10 \pm 0.14^{\mathrm{b}}$ \\
Arg $^{* *}$ & $1.10 \pm 0.04^{\mathrm{B}}$ & $0.56 \pm 0.01^{\mathrm{C}}$ & $3.40 \pm 0.04^{\mathrm{A}}$ \\
Pro $^{* *}$ & $0.72 \pm 0.01^{\mathrm{A}}$ & $0.53 \pm 0.03^{\mathrm{B}}$ & $0.33 \pm 0.01^{\mathrm{C}}$ \\
Cys $^{* *}$ & $0.40 \pm 0.03^{\mathrm{C}}$ & $0.96 \pm 0.08^{\mathrm{B}}$ & $1.61 \pm 0.04^{\mathrm{A}}$ \\
Trp $^{\text {Total amino }}$ & - & - & - \\
acids & & & $27.423^{\mathrm{A}}$ \\
\hline
\end{tabular}

Unit: Amino acids g/100 g dry Pleurotus. ** Indicates that amino acid analysis of variance $\mathrm{F}$ test reached a significant difference at the 0.01 level. * Indicates that amino acid analysis of variance $\mathrm{F}$ test reached a significant difference at the 0.05 level. A, B, C indicates that there is no difference in the same characteristic when reaching a significant difference at 0.01. a, b, c indicates that there is no difference in the same characteristic when reaching a significant difference at 0.05 . Q test in least significant ranges is used in multiple comparisons.

The contents of eight other amino acids in CPAE is higher than CP and WP. The content of Arg in CPAE is higher than WP by $209.1 \%$ and higher than CP by $507.1 \%$. The content of Met in CPAE is higher than WP by $298.9 \%$ and higher than CP by $66.9 \%$. The content of Try in CPAE is higher than WP by $123.5 \%$ and higher than CP by $81 \%$. The content of Ile in CPAE is higher than WP by $68.2 \%$ and higher than CP by $121.9 \%$. The content of the seven essential amino acids assessed, except for Thr and Val, in CPAE with $2.3 \mathrm{~g} / 100 \mathrm{~g}$ extract, is higher than CP and WP. The content of Thr in CPAE is lower than WP and CP. The content of Val in CPAE is lower than WP.

As illustrated in Table 5, the treatment with asafoetida extract showed a marked effect on percentage composition of essential amino acids. At the concentration of $2.3 \mathrm{~g} / 100 \mathrm{~g}$, asafoetida extract showed the highest content of total necessary amino acids $(49.79 \%)$ followed by egg $(49.7 \%)$, CP (43.20\%), WP (40.74\%) and the FAO/WHO recommendations (35\%).

As illustrated in Table 6, scoring of protein content of Pleurotus fruiting body is the highest (70.2\%) for asafoetida extract $(2.3 \mathrm{~g} / 100 \mathrm{~g})$ followed by CP (57.7\%), and WP (43.3\%). As illustrated in Table 7, scoring of necessary amino acids components of fruiting bodies is the highest $(73.2 \%)$ in $\mathrm{CP}$, followed by CPAE with $2.3 \mathrm{~g} / 100 \mathrm{~g}$ extract (70.3\%), and WP (55.8\%).

Wild Pleurotus ferulic lives specially in the roots of asafoetida, decomposing it as its own nutrient and suggesting that there must be some chemicals there that affect its growth. In the experiment, Pleurotus ferulic was extracted with $95 \%$ ethanol and concentrated to give a complex mixture of chemical components. These chemical components play an important role in amino acid conversion, synthesis and accumulation. In the experiment, we added asafoetida extract to Pleurotus ferulic culture in appropriate proportions. When adding higher contents of asafoetida extract, the growth of Pleurotus mycelium and fruiting bodies was inhibited to some extent. This will definitely affect nutrient composition accumulation in fruiting bodies, and amino acid contents. We are most interested in some 
phenomena in the experiment. The content of some amino acids in CP is higher than CPAE and WP, while the content of some other amino acids is higher in CPAE than CP and WP, especially Arg and Met. In the experiment, the irregular change of Pleurotus ferulic amino acids must be in correlation with some chemicals in asafoetida extract. Now we can only speculate that these asafoetida extract chemicals stimulate or inhibit the physiology and/or metabolism of Pleurotus, or is used directly as a source of amino acids. Now the principle of the relationship is not clear.

Table 5. Essential amino acid components of pleurotus fruiting body.

\begin{tabular}{cccccc}
\hline Amino acids & WP \% & CP \% & $\begin{array}{c}\text { CPAE with } \mathbf{2 . 3} \text { g/100 g } \\
\text { extract \% }\end{array}$ & Egg \% & $\begin{array}{c}\text { FAO/WHO } \\
\text { \% }\end{array}$ \\
\hline Thr & 4.66 & 4.35 & 3.11 & 5.1 & 4 \\
Val & 5.51 & 3.66 & 3.52 & 7.3 & 5 \\
Met + Cys & 1.95 & 5.34 & 6.69 & 5.5 & 3.5 \\
Ile & 4.03 & 3.50 & 5.83 & 6.6 & 4 \\
Leu & 7.21 & 6.79 & 8.75 & 8.8 & 7 \\
Phe + Tyr & 11.45 & 14.23 & 17.87 & 10 & 6 \\
Lys & 5.93 & 5.34 & 4.01 & 6.4 & 5.5 \\
Total content & 40.74 & 43.20 & 49.79 & 49.7 & 35 \\
\hline
\end{tabular}

Table 6. Scoring of protein content of Pleurotus fruiting bodies.

\begin{tabular}{cccc}
\hline Amino acids & WP & CP & $\begin{array}{c}\text { CPAE with 3.3 g/100 g } \\
\text { extract }\end{array}$ \\
\hline Thr & 111.5 & 98.1 & 77.7 \\
Val & 92.1 & 57.7 & 70.2 \\
Met + Cys & 43.3 & 111.6 & 190.9 \\
Ile & 74.5 & 61.0 & 145.6 \\
Leu & 99.9 & 88.8 & 124.8 \\
Phe + Tyr & 139.6 & 163.7 & 297.3 \\
Lys & 113.1 & 96.0 & 72.8 \\
Score of protein content & 43.3 & 57.7 & 70.2 \\
\hline
\end{tabular}

Table 7. Scoring of essential amino acid components of Pleurotus fruiting bodies.

\begin{tabular}{cccc}
\hline Amino acids & WP & CP & $\begin{array}{c}\text { CPAE with 3.3 g/100 g } \\
\text { extract }\end{array}$ \\
\hline Thr & 116.6 & 108.7 & 77.9 \\
Val & 110.2 & 73.2 & 70.3 \\
Met + Cys & 55.8 & 152.4 & 191.2 \\
Ile & 100.8 & 87.5 & 145.9 \\
Leu & 103.0 & 97.1 & 125.0 \\
Phe + Tyr & 190.8 & 237.1 & 297.8 \\
Lys & 107.9 & 97.1 & 72.9 \\
Score of essential amino & 55.8 & 73.2 & 70.3 \\
acids components & & &
\end{tabular}




\subsection{Comparative Analysis of Volatile Components in Three Kinds of Pleurotus'}

In order to identify putative active compounds present within the asafoetida extract, gas chromatography and MS were employed. The chemical composition of the extract is reported in Table 8. The extract from the $\mathrm{CP}$ group was characterized by a very high content of diethyl succinate (14.9\%), 2-methylsuccinic acid 2-hydroxysuccinimide ester (27.29\%), benzoic acid 2-octyl ester (10.17\%), diisobutyl phthalate (11.99\%) and hexadecanoic acid ethyl ester (11.91\%). The extract from the treatment group $(2.3 \mathrm{~g} / 100 \mathrm{~g})$ was characterised by a very high content of guaiol $(34.01 \%)$, 2-methylsuccinic acid 2-hydroxysuccinimide ester (17.86\%), and diisobutyl succinate (18.27\%). The extract from the wild pleurotus group was characterised by a very high content of diethyl succinate (11.28\%), guaiol (11.32\%), diisobutyl succinate (22.78\%), 3,3-dimethyl-2,4,5-3-thiooctane (12.79\%), $n$-pentadecanoic acid ethyl ester (9.78\%) and 9,12-octadecadienoic acid ethyl ester $(9.25 \%)$. The major components thus displayed some differences, which were affected by the treatment with asafoetida extract. Smaller differences occurred between group treated by asafoetida extract and wild pleurotus ones.

Table 8. Comparative analysis of volatile components in three kinds of pleurotus by GC/MS.

\begin{tabular}{|c|c|c|c|c|}
\hline Number & Chemicals & $\mathbf{C P}$ & $\begin{array}{c}\text { CPAE with } \\
2.3 \mathrm{~g} / 100 \mathrm{~g} \\
\text { extract } \%\end{array}$ & WP\% \\
\hline 1 & $\beta$-Pinene & 0.38 & 0.82 & 0.07 \\
\hline 2 & Limonene & 0.01 & 0.07 & 0.05 \\
\hline 3 & $\begin{array}{l}\text { 5,11-Diene-nordihydroguaiaretic } \\
\text { acetate }\end{array}$ & - & 0.04 & 0.03 \\
\hline 4 & $\beta$-Sitosterol & 0.50 & 1.24 & 3.01 \\
\hline 5 & Diethyl succinate & 14.9 & 3.99 & 11.28 \\
\hline 6 & Guaiol & - & 34.01 & 11.32 \\
\hline 7 & $\begin{array}{l}\text { 2-Methylsuccinic acid-2 - } \\
\text { hydroxysuccinimide ester }\end{array}$ & 27.29 & 17.86 & - \\
\hline 8 & Diisobutyl succinate & 0.03 & 18.27 & 22.78 \\
\hline 9 & Benzoic acid-2'-octyl ester & 10.17 & 1.87 & 4.02 \\
\hline 10 & 3,3-Dimethyl-2,4,5-3-thiooctane & 0.59 & 5.58 & 12.79 \\
\hline 11 & $n$-Eicosane & 2.48 & 0.25 & 0.54 \\
\hline 14 & Diisobutyl phthalate & 11.99 & 1.00 & 2.11 \\
\hline 12 & $n$-Pentadecanoic acid ethyl ester & 4.43 & 4.76 & 9.78 \\
\hline 13 & Hexadecanoic acid ethyl ester & 11.91 & 1.76 & 3.55 \\
\hline 14 & 9,12-Octadecadienoic acid ethyl ester & 1.51 & 4.54 & 9.25 \\
\hline 15 & $\begin{array}{l}\text { (Z)-9-Octadecenoic acid ethyl ester; } \\
\text { ethyl cis-9-octadecenoate }\end{array}$ & 0.30 & 0.54 & 1.16 \\
\hline 16 & $\begin{array}{l}\text { cis-Octadeca-9,12-dienoic acid ethyl } \\
\text { ester }\end{array}$ & 0.42 & 0.13 & 0.26 \\
\hline 17 & Linoleic acid & 2.62 & 0.15 & 0.36 \\
\hline 18 & (9Z,17Z)-Octadecadienal & 0.01 & 0.86 & 1.80 \\
\hline 19 & $\begin{array}{l}9(Z), 12(Z), 15(Z) \text {-Octadecatrienoic acid } \\
\text { methyl ester }\end{array}$ & 0.11 & 0.02 & 0.01 \\
\hline
\end{tabular}




\section{Experimental Section}

\subsection{Materials}

Asafoetida and Pleurotus ferulic were collected from Qinghe County, Xinjiang Province, China. The Pleurotus ferulic strain used in this study was isolated from Wild Pleurotus ferulic and has been maintained in the culture collection of the Laboratory of Microorganism Physiology, Xinjiang agricultural university, China. The asafoetida was identified as Ferula sinkiangensis K. M. Shen.

\subsection{Chemicals}

Cottonseed hull, wheat bran, corn flour, high pressure polypropylene culture bags, rings, lime powder (all bought on the market); amino acid standards (Sigma Corporation); citric acid, boric acid, hydrochloric acid, sodium hydroxide, lithium hydroxide (all AR; Beijing Reagent Factory).

\subsection{Methods}

\subsubsection{Preparation of Asafoetida Extract}

The asafoetida was dried, pulverized and extracted $(20.0 \mathrm{Kg})$ with $95 \% \mathrm{EtOH}(60.0 \mathrm{~L})$ at $75{ }^{\circ} \mathrm{C}$ for $5 \mathrm{~h}$ under reflux, and the supernatant was removed. The combined supernatant was then concentrated to obtain asafoetida extract.

\subsubsection{Cultivation of Pleurotus ferulic}

The culture material used for Pleurotus ferulic cultivation, was composed of $80 \%$ cotton seed hull, $15 \%$ wheat bran, $5 \%$ corn flour and $65 \%$ water. Plastic bags $(9 \mathrm{~cm} \times 20 \mathrm{~cm} \times 0.04 \mathrm{~cm})$ containing substrates $(135 \mathrm{~g})$ were pasteurized at $121^{\circ} \mathrm{C}$ for $2 \mathrm{~h}$ (temperature ramp to $35{ }^{\circ} \mathrm{C}$ was about $3 \mathrm{~h}$ ), allowed to cool for $1 \mathrm{~h}$ to ca. $35^{\circ} \mathrm{C}$, then inoculated with $0.5 \%(\mathrm{w} / \mathrm{w})$ Pleurotus ferulic Strain. The inoculated substrates were incubated in an enclosed room at $18-25{ }^{\circ} \mathrm{C}$ for 2 days. To stimulate fruiting, fresh air was introduced to maintain $<1,000 \mathrm{ppm} \mathrm{CO}_{2}$. Each treatment contains fifty plastic bags.

\subsubsection{Initial Formation Time of Pleurotus Buds}

To observe the effects of asafoetida extract with different concentration on growth of Pleurotus mycelium and fruiting bodies, it was cultured on the above-mentioned culture material. Length of mycelium was examined once at an interval of 7 days for 35 days. After that, length of mycelium was examined twice at an interval of 7 days until it filled the whole plastic bags. Twenty days after that, time of formation and number of Pleurotus buds were recorded.

\subsubsection{Yield of Pleurotus of Each Treatment Batch}

The fruiting bodies of Pleurotus were collected from every plastic bag after spore maturation. The fresh Pleurotus were air dried for several days in outdoor shade. Total weight of every treatment batch and average weight of every plastic bag were calculated. 


\subsubsection{Analysis of Amino Acids Composition in Asafoetida Pleurotus Fruiting Bodies}

The content moisture and total $\mathrm{N}$ were determined according to procedures described by the AOAC (1990). The content of amino acids was determined using an A-200 amino acid analyzer (INGOS, Prague, Czech Republic). The analytical procedure applied was in accordance with the recommendations of the manufacturer. The freeze-dried material was hydrolyzed in $6 \mathrm{M} \mathrm{HCl}$ for $24 \mathrm{~h}$ at $110^{\circ} \mathrm{C}$. After cooling, filtering and washing, the hydrolysate was evaporated in a vacuum evaporator at a temperature below $50{ }^{\circ} \mathrm{C}$ for sulfur-containing amino acids and below $60{ }^{\circ} \mathrm{C}$ for others amino acids, the dry residue being dissolved in a buffer of $\mathrm{pH}=2.2$. The prepared sample was analysed using the ninhydrin method. Buffers of $\mathrm{pH}$ 2.6, 3.0, 4.25, and 7.9 were used. The ninhydrin solution was buffered at $\mathrm{pH}$ 5.5. A column $370 \mathrm{~mm}$ in length was filled with Ostion ANB INGOS ionex (Czech Republic). The temperature of the column was $55-74{ }^{\circ} \mathrm{C}$ and that of the reactor was $120^{\circ} \mathrm{C}$. The determination of the sulfur-containing amino acids, methionine and cystine, was carried out by means of oxygenating hydrolysis, using a mixture of formic acid and hydrogen peroxide (9:1) at $110^{\circ} \mathrm{C}$ for $24 \mathrm{~h}$. After cooling, the sample was processed as with acid hydrolysis. Buffers of $\mathrm{pH} 2.6$ and 3.0 were used; the temperature of the column was $60^{\circ} \mathrm{C}$ and that of the reactor was $120^{\circ} \mathrm{C}$. The calculations were carried out according to the external standard.

The composition of amino acids was also expressed as $\mathrm{g} / 16 \mathrm{~g} \mathrm{~N}$ to estimate the quality of the protein in fruiting body of the pleurotus by comparing it with the FAO/WHO (1970) pattern. On the basis of the amino acid composition, the CS index was calculated using the Amino Acid Content Of Foods and Biological Data on Proteins (1970) [9].The objective function was established [Equations (1) and (2)]:

$$
C S=(A x)(E e) 100 /(A e)(E x)
$$

where Ax- necessary amino acids content $(\mathrm{g})$ in tested protein; Ae- necessary amino acids total content $(\mathrm{g})$ in tested protein; Ex - necessary amino acids content $(\mathrm{g})$ in egg protein; Ee-necessary amino acids total content $(\mathrm{g})$ in egg protein. The AAS index was estimated using the Bano method [10]:

$$
A A S=A x(\mathrm{mg} / \mathrm{g}) 100 / A e(\mathrm{mg} / \mathrm{g})
$$

where Ax-necessary amino acids content $(\mathrm{g})$ in tested protein; Ae-necessary amino acids total content (g) in tested protein.

\subsection{Gas Chromatography-Mass Spectroscopy (GC-MS) Analysis}

Samples of volatile compounds were diluted in methyl tert-butylether (MTBE; 1:100) and analysed in an Agilent GC-MS apparatus equipped with an Rtx-5 SIL fused-silica capillary column ( $30 \mathrm{~m} \times 0.25 \mathrm{~mm}$ internal diameter, $0.25 \mu \mathrm{m}$ film thickness, Restek). Helium $(0.8 \mathrm{~mL} / \mathrm{min})$ was used as a carrier gas. Samples were injected in the split mode at a ratio of 1:10-1:100. The injector was kept at $250{ }^{\circ} \mathrm{C}$ and the transfer line at $280^{\circ} \mathrm{C}$. The column was maintained at $50^{\circ} \mathrm{C}$ for 2 min and then programmed to $260{ }^{\circ} \mathrm{C}$ at $5{ }^{\circ} \mathrm{C} / \mathrm{min}$ and held for $10 \mathrm{~min}$ at $260{ }^{\circ} \mathrm{C}$. The MS was operated in the EI mode at $70 \mathrm{eV}$, in the $\mathrm{m} / \mathrm{z}$ range $42-350$. The identification of the compounds was performed by comparing their retention indices and mass spectra with those found in the literature and supplemented by the Wiley \& QuadLib 1607 GC-MS libraries. The relative proportions of the volatile constituents 
were expressed as percentages obtained by peak area normalization, all relative response factors being taken as one. The Kovat indices were determined from the retention times after co-injection with $n$-alkanes.

\section{Conclusions}

Pleurotus ferulic cultivation experiments indicated that as the the amount of asafoetida extract additive increased, growth of mycelium and the formation time of buds were faster, and that yield of Pleurotus ferulic fruiting bodies was enhanced. However, an overdose of asafoetida extract hampered the growth.

Results of amino acids analysis showed that CPAE with $2.3 \mathrm{~g} / 100 \mathrm{~g}$ asafoetida extract addition had the highest content of total amino acids as well as essential amino acids. WP had a higher content of total amino acids and essential amino acids than CP. In addition, CPAE with $2.3 \mathrm{~g} / 100 \mathrm{~g}$ had the highest score of protein content of Pleurotus fruiting bodies, while WP had a higher score than CP. In the score of necessary amino acids components of fruiting bodies, CP had the highest score, while CPAE was higher than WP.

The content of asafoetida had a great influence on the volatile components of Pleurotus ferulic, influencing the flavor, making the volatile components of CPAE more similar to that of WP, and providing an effective way for enhancing the quality and flavor of cultivated Pleurotus ferulic.

\section{References}

1. Huang, N.L. Chinese Large Fungi Colorful Illustrations, 1st ed.; China Agriculture Press: Beijing, China, 1998; pp. 95-96.

2. Mao, X. L. Economic Fungi of China, 1st ed.; Science Press: Beijing, China, 1998; p. 30.

3. Shan, R.H.; Yu, M.L. Flora of China; Science Press: Beijing, China, 1992; Volume 55, pp. 85-117.

4. Li, Y.L.; Chen, B.S.; Li, R.C. Research on growth regulators on growth of asafoetida pleurotus. Mycelium. Edible Fungi 2004, 3, 22-23.

5. Li, G.X.; Shao, S.G.; Li, Y.J. Effect of Hormone on the growth and yield of pleurotus eryngii var.nebrodensis.Chin. Edible Fungi 2004, 23, 37-38.

6. Tian, H.X.; Liu, X.G.; Jia, X.H. Effect of Growth of pleurotus ferulae on adding powder of ferula sinkiangensis in culture medium. Chin. Edible Fungi 2008, 27, 30-33.

7. Li, Z.H.; Fan, Y.M.; Wu, H.Q; Bing, L. Ferulic pleurotus cultivation comparative test compound content of ferulic. Edible Fungi 2005, 2, 42-43.

8. Li, M.; Jian, Z.Y.; Li, X.W. Influence of some samphire Chinese medicine extract on braun pleurotus mycelium growth. J. Anhui Agri. Sci. 2006, 34, 5499-5500.

9. FAO. Amino Acid Content of Foods and Biological Data on Proteins; FAO: Rome, Italy, 1970; No. 24, pp. 5-6. 
10. Bano, Z.; Rajarathram, S. Pleurotus as a nutritious food. In Tropical Pleurotuss-Biological Nature and Cultivation Methods; The Chinese University Press: Beijing, China, 1982; pp. 363-380.

(C) 2010 by the authors; licensee Molecular Diversity Preservation International, Basel, Switzerland. This article is an open-access article distributed under the terms and conditions of the Creative Commons Attribution license (http://creativecommons.org/licenses/by/3.0/). 